\title{
Economic globalization and its challenges in developing countries with emphasis on Iran
}

\author{
Mostafa Alipour KHONAKDARI ${ }^{1}$, Nemat HosseinZAdEH ${ }^{*}{ }^{2}$, Zahra MiralaEI ${ }^{3}$, \\ Maryam Yaghoub POUR ${ }^{4}$, Azam MolAIE ${ }^{5}$ \\ ${ }^{1}$ MA in International Relations, Islamic Azad University, Science and Research, Qom, Iran \\ ${ }^{2}$ Lecturer Department of Architecture, Sama Technical and Vacatinal training College, Islamic \\ Azad University, Islamshahr, Branch, Islamshahr, Iran ( Nemat.1986@yahoo.com ) \\ ${ }^{3}$ Department of Urban Planning, Shahre -Quds Branch, Islamic Azad University, Tehran, Iran \\ ${ }^{4}$ Master of Business Administration, a researcher at the International Bureau of the Central Bank of the Islamic \\ Republic of Iran \\ ${ }^{5}$ Master Student of Geography and Urban Planning, Islamic Azad University of Semnan, Semnan, Iran
}

\begin{abstract}
Globalization is seen beyond avoidance Due to the expansion and strengthening of mass communication and media are and quickly in all dimensions and aspects of human life, especially culture, society, economy and politics has penetrated And all aspects of human life is affected. Understandings of the phenomenon and the challenges and strategies for dealing with the most important responsibilities of scientists and experts from different countries are at present. The present study was to understand the importance and challenges of globalization and the threats against the Islamic Republic of Iran to analyze this phenomenon and Develop and submit to the demands of the 21st century, the country's main strategies in dealing with globalization of culture, society, economy and politics is discussed. The results show that the strategies for dealing with globalization, It can be said that the implementation of strategies and opportunities that it creates For the protection of cultural and social identity important part of our identity is a need to strengthen and enhance the level of cultural, social and economic Smarmy efforts Protecting and preserving the rich culture and customs of the whole Islamic world is ready to face the new approaches to the interests of our country.
\end{abstract}

Keywords: globalization, global globalization of culture, society and Economics Globalization Challenges and Strategies.

\section{1- Introduction}

Globalization is one of the key concepts in the fields of politics, culture and economy in recent decades has been the attention of scholars and policy makers, So that this concept may be one of the most popular and widely used concepts in the humanities knew that in time it is declared new horizons. Waters 'globalization' is a social process in which the constraints of geography on social and cultural ties and economic pervades Lost and people are increasingly aware of these restrictions. Globalization on the eve of the 21 st century, a symbol of various phenomena that span a wide range of personal and social development And the evolution of human communication announced. This change not only the technical and economic indicators, but little change in the qualitative transformation of the political, the cultural and social aspects,

\footnotetext{
* - Corresponding Author
} 
it seems that the theoretical position of capitalism as the dominant global production has stabilized. And accordingly, any adaptation of national interest calculated in accordance with the rules of international and domestic and international pressure balancing of the biggest challenges in the era of globalization (Amoi, 1390, p. 2). Society as well as social life with economic, cultural, social and political world is linked cannot be indifferent to the global process. Interaction with the process and optimum utilization of it, on the one hand and on the other hand understanding of this phenomenon requires determination and planning goals and interests and initiative to achieve them. On this basis, depending on the nature of the political system of the Islamic Republic of Iran, Cultural, social and historical context to engage in the international system requires an understanding of globalization and the overall design of the compliance or non-compliance with the intellectual and practical concept is pervasive. It seems that in the course of Iran's engagement with the international system that are missing links Faced or compliance or global system, the country is faced with complexity (Rahimi, 1390, p. 3). This paper seeks to answer this question is that the guidelines and policies of the Islamic Republic of Iran in the face of globalization strategies, culture, economy, society, politics and principles based on what basis? what kind of challenges facing the sector in cultural, social, economic and political of Islamic Republic of Iran in the era of globalization there? Finally, strategies for taking advantage of the opportunities and confront the threats of globalization, how? To answer these questions, first term globalization as a phenomenon and the extent specified, The globalization of cultural, social, and economic and social cohesion in the era of globalization has been checked and strategies, challenges, opportunities and threats of globalization are discussed and evaluated, Finally, the argument has been presented to the conclusion.

\section{The objectives of the research}

Strategies Islamic Republic advantage of opportunities and challenges, threats of cultural, social, and economic:

1. Identify effective strategies and challenges the cultural sector in metropolitan cities in the era of globalization.

2. Identify effective strategies for social sector and challenges in large cities in the globalization era.

3. Economic sectors and identify effective strategies to deal with challenges in metropolitan cities in the era of globalization.

\section{Research Methodology}

This survey is useful because after doing research, the results obtained can be used in order to improve the cultural, social, economic contribute. Data collection methods and data (literature and composition) is. In order to compile the literature using the library resources to identify strategies and challenges of social, cultural, economic, Islamic Republic of Iran is discussed And finally, to identify opportunities and threats in the era of globalization is discussed.

\section{Concepts and Theoretical Research A- Concepts and Definitions of Globalization}

The term globalization of the Western countries, especially the United States of America has been proposed and in the semantic sense can be regarded as an expression of the wishes of its leaders. But globalization also can be considered as a phenomenon affecting and affected in a social process, a variety of effects and consequences. The concept of globalization from the mid- 
1980s onwards was more common. Expand it to a particular concept of sociology at the University of Pittsburgh's most indebted. World as a single location at a more abstract level of the international system, governments are actively engaged in the following activities:

Division of power at the international level or at the continental level to establish collective security, value creation and global norms, for example in the field of social and political rights, The use of nuclear power and the principles relating to the use of force, adjusting the distribution of the international classification of countries through the reallocation of economic resources and coordinate the exchanges between countries in the fields of trade, migration, Cultural functions, etc., in which the three major gap in the international system to prevent systematic world are facing: Religious divide, divide legal - diplomatic, industrial divide.

Mac depends on the general concept of globalization such as the: Increase the number of links and interactions with the government (and thus beyond the communities) to spread fuel, the new system will make a world. Globalization refers to the process through which events, decisions and activities in one part of the world can important implications for individuals and communities in very remote parts of the globe is on. (Vdad.ach Imran, 1370). And Thomas Friedman believes that the issue of the World "Globalization is not just an economic process and on the other hand also is not a passing wave. But like all previous international system directly or indirectly, domestic politics, foreign economic and shapes almost all countries. "(Thomas Friedman, 1380, p. 15). Another American scholar James Roznov, Neamt about various topics such as globalization and the relationship between states: "The globalization of communication between different levels of integration of economic, political, cultural and ideological reproduction planning, cross-border communication industry, expanding investment markets, standards and consumer countries as a result of conflict and struggle of indigenous and immigrant groups covers ".

Globalization and its impact on the David Harvey argues that: "Globalization has entered a new stage of compression of time and space, which is confusing and detrimental impact on the process of political, economic, social and cultural life and the balance of class power". But the complexity of globalization albero Martin says: Globalization, but distinct set of complex processes in the areas of politics, economy, culture and thought that everything will change, but emerged from the history. First, this is a process, not a project, the latter being universal. Third, it is huge and covers every aspect of your life "(Said, 1385, p. 80). Globalization is defined as follows:

"The increasing compression of time and space due to the rising world population and relatively more or less conscious of the international community will be merged. In other words, globalization is a process that involves the individual and society in the world encapsulation bonded "(Tamylsvn, 1381, p. 20).

\section{B. Culture and Globalization}

One of the most important aspects of the globalization process is the cultural dimension. The process by modern information technology, all the different boundaries, especially influenced by the cultural barriers. Globalization with components such as technical information, computer, satellite TV, internet, all aspects of political, social and cultural Ratht been overwhelmed. Globalization is an important component of science. Today, science and technology are the elements influencing the culture and nature and nature are universal. It is unacceptable that a country's border with credit to the knowledge, open technologies in various fields of science, but it is prevented from enjoying culture. Advanced industrial countries in the north, such as cars, a 
phenomenon that has great development in the areas of transportation, urbanization, customs, laws and norms have provided consumers south. Satellite TV and also have the same categories. The advantages and benefits of a phenomenon no one can give the advantage to the values and norms (Kazemi, 1380: 271). Thus, cultural globalization, it affects the meaning and identity to become a relative concept. Or, as Waller Stein found in the new world is emerging and the difficult identity is uncertain, In other words, the relative stability that had emerged in the twentieth century through national attitudes in the light of global identity claim is somewhat faded. And decision-making in this area is faced with a serious problem. This means that the identity of national identity, globalization has given way to a resource (Honorary, 1380, p: 3338). The ratios of the absolute cultural value system lose its simplistic and turn towards cultural patterns. In this case, people find their identities combination. What and who is not comparable with the standards of the local culture and go on to universal standards (A. Rose, 1386, pp. 2818).

\begin{tabular}{|c|l|}
\hline \multicolumn{2}{|c|}{ Table 1: Summary definitions of culture } \\
\hline Source & \multicolumn{1}{|c|}{ Definition } \\
\hline J. c. sendes & A belief system that is shared among individuals. \\
\hline C. Oreilly & Ethical values that are widely shared among most people. \\
\hline $\begin{array}{c}\text { \&T. Petters } \\
\text { R. ll. Waterman }\end{array}$ & $\begin{array}{l}\text { A set of shared values and symbolic meanings are attached to the stories, myths, and } \\
\text { proverbs single word transfers. }\end{array}$ \\
\hline E. Shein & $\begin{array}{l}\text { The basic model assumes a certain length of time in dealing with the problems To } \\
\text { maintain internal consistency and compliance with environmental changes is discovery } \\
\text { and invention. }\end{array}$ \\
\hline $\begin{array}{c}\text { \&T.M. Kouzes } \\
\text { P.Z. Pso }\end{array}$ & $\begin{array}{l}\text { A set of shared beliefs and lasting through a variety of tools to create symbolic meaning in } \\
\text { life are transferred. }\end{array}$ \\
\hline Margret Mead & $\begin{array}{l}\text { Set of learned behaviors, beliefs, customs and traditions that are shared among a group of } \\
\text { people. And sequential manner by those who enter the community, they are learned and } \\
\text { applied. }\end{array}$ \\
\hline
\end{tabular}

Source :( Manuel, 1990p:250)

\section{C. economic globalization}

Joseph globalization of the economy "requires close integration of the world economy by increasing the flow of goods, services, capital and labor" is defined (Joseph: 1386, 24). Economic globalization has exacerbated the flow of goods, services, information, investment and production factors at international level implies that led to the economic integration of the world, Origin of the main principles of economic globalization, trade and commerce. Manufacturers and consumers can trade at a distance from each other are connected to each other and often common sense and create interdependence between them (Quoting Joseph, 1383). The globalization of the economy, "the border is removed, national borders, local borders, political constraints, physical distance, difference, the difference between money and so they separated the market economy. Globalization of economic markets by reducing or eliminating the borders back and in the context of a global market and global competition and the standards (Renan, 1383 S8).

\section{Community and global links}

In the modern era, and the distance of time and space is much higher than in the previous period and Relations between the government and social events are interconnected and equally 
distant. "Globalization" is basically the same process of discovery is relevant, As far as the relationship between the various areas of social practices across the entire surface of the earth in the network. 'Globalization' can be defined as the intensification of social relations at the global level. The ties that bind the locations are so far apart each local event affects other events that shaped miles away. And vice versa local transformation as a peripheral expansion of social relations across time and space is actually part of the globalization process. Indeed, "globalization" means intensifying those social relations linking together distant geographical locations and this relationship in a way that through which events in one part of the world are affected by the events of miles on it. And vice versa, "says Mac grave," "globalization" means increasing the number of links and interactions that are beyond the skirt makes the global unfolds and new system (Gybrna, 1378: 225).

\section{Analyzes}

With respect to issues concerning the structural system of the Islamic Republic of Iran metropolises such as the lack of urban policy and the distribution of population in the country While urban development plan, being unable to meet the needs of a broad set of rules and regulations that exist in the metropolis. The data analysis of both the challenges and effective strategies for the development of large cities according to the cultural, economic, social, will be discussed:

\section{Part I: the challenges facing the cultural, social and economic Iran in the Age of Globalization}

\section{The challenges of the cultural sector}

In the era of globalization is that it leaves the greatest impact threats from alien cultures and its destructive effects on the customs, traditions and values of their culture. Because of the globalization of culture and identity will fade municipal borders and border opening will intensify and Norms of the culture, customs and traditions as much as some people undermine cities and urban cultures of the world to feel threatened by the invasion, Because the influx of media and cultural identity of the towns affected and eventually collapsing. The process of globalization has also affected the local community identity and cultural mistrust and fragmentation of the social and cultural systems has increased and Ultimately led to the radical transformation of cultural values, This tradition of removing the original cultures and countries have intensified And the creation of virtual space and land as a place of identity undermines and social life of the state the space where to turn. The interactions of the different countries together international E-regional identities are formed; this would reduce state control over land and identity issues and causes the release of Social Affairs of the dominant position.

\section{Economic Section challenges}

With regard to economic problems and obstacles in some areas such as information systems, lack of investment in research and development industry And restrictive regulations, economic growth and development in the country in various areas has been slow going. This volume of economic exchange and flow of global capital in cities than in cities such as Dubai, Hong Kong, Singapore, which is very low, and it is quite evident. Foreign investments in post-war system in our country is very low Because tariffs in the country (approx 4/32 percent) compared to that of butter ( $5 / 3$ percent) is high and This leads to restrictions on foreign investment in Iran and other countries. Other challenges facing the sector in the age of globalization in the country can be traced to the following factors each of which turn obstacles and difficulties for the country's economic system to bring: 
- The lack direct relationship between industrial employment and urbanization.

- Extensive damage to the country's economic system, the digital system.

- Damage caused by the difference in the world of production and income.

- Problems related to the distribution of economic resources in cities.

\section{The challenges social sector}

Since each country has specific cultural and social systems in the era of globalization and social interactions with other social conflicts in towns and cities can create imbalances and social stability. And thus disturb the ecology of cities and urban ecology separation switching which can fade the territorial implications. iran also Mstsny this rule is not because they are constantly interacting with each other, this would result in the loss of identity, weaken and eliminate the word citizen who is in a level position (Nasiri, 1388, p. 25).

\section{Part II: Strategies for the cultural, economic, social and Iran in the Age of Globalization 1. Strategies for the cultural sector}

Prevention, strengthen the local economy in which the procedures and policies are subject to shrinkage, Because local and highlighting the new norms, beliefs and norms of qualification to prevent and thereby strengthen the normative beliefs as the foundation stone for strengthening the culture of the world. The city's cultural integrity of the collective action is the main factor after taking into account the change in organizational culture in order to prevent people and accelerating the adoption of a positive wave of globalization, it seems necessary to note the following:

- Formation of a committee to identify corporate identity.

- Determine the recognition of indigenous cultures.

- Creation of cultural unity through Gftgy cultures and civilizations.

- Taking advantage of opportunities arising from the development of networks and the media to highlight cultural features, local towns.

- Creation of stable fixed identity of the citizens of the town's historical narrative.

- Emphasis on the extent of reconstruction, reconstruction of historic towns and identity.

\section{Strategies for social sector}

With revealing the nature of social conflict perspective for social justice in cities and towns cause a participatory democracy in the cities and among citizens. the importance of the sector, civil society and non-governmental organizations, cities and citizens to participate more fully the use of collective wisdom, also can be said that discussion and analysis of issues and needs in the perspective of citizens, according to the formulation of objectives Social programs in order to respond to their needs is maximized. So what is necessary in the social sector strategies considered are as follows?

- Recognition of the skills, capabilities and strengthen funds in the interaction.

- Strengthening of social identity and social communication is possible and meaningful lives.

- Supporting local creative urban communities in order to create peace and prosperity.

- Development of new partnerships between governments and private companies in order to strengthen social and national creativity.

- Establish a healthy relationship between national identity and globalization.

- Choose the correct insight about the social problems of the cities. 


\section{The economic Strategies}

Given the importance and urgency of the economic sector and plays a key role in the world, the creation of infrastructure for cities to meet the needs of multinational, and competence as a global city, providing a safe place for investment and economic activity, social and cultural rights on a global scale is essential for the metropolises of the country. because this process leaves a profound influence on the phenomenon of urbanization, The proper context of the cities in order to adapt them to meet the minimum needs of the global economy and creating a competitive environment in the community and improve the competitiveness of cities that the process is crucial, In this regard, a number of important economic policies of the Islamic Republic of Iran, with appropriate reference to the 21st century:

- Capability, marketing, development and production and provide after sales service to the quality standards accepted by the market and the global economy.

- Creating the right environment for economic and consistency between macroeconomic policy and international politics of the country.

- Reduce tariffs and other trade restrictions to facilitate the import and export of goods and boost global trade.

- The wise policy of détente in order to obtain the identity and global identity for cities to invest.

- Encouraging neighbors south of the Persian Gulf and Central Asia to build up a global area of cities.

- Geographic focus on creating world-class financial institutions in metropolitan Tehran.

- Reducing the simple average tariff rate as other neighboring countries.

- The creation of a networked economy which components communicate with each other deeply.

- Create a competitive advantage based on the relative position within the network of cities economy.

- Replace the virtual and electronic banking in the country (virtual money to replace ecommerce).

- The importance of considering the potential economic and cities affected by national and regional circumstances.

- According to some characteristics of a place to connect with other cities in neighboring cities.

- Adopt an understanding of the interrelationships between development policy and the national economy.

- Encourage and guide the development of urban areas along the axis of the inevitable interaction with other major cities.

- Creation of the space division of labor and specialization of settlement centers and institutions active in the urban areas.

- Identify all the factors that led to the city's economy and boost their productivity.

- The digital economy and business travel markets in the world geographical space the space.

- Integration of national economies via international trade and investment.

- Clarify the economic activities of firms and markets. 


\section{The strategy of the Islamic Republic in Fight against Threats and the advantage of the opportunities of globalization.}

For the protection of cultural identity is actually an essential part of our homeland and identity is important to strengthen and enhance their cultural different levels of Gmarym efforts, Protecting and preserving the customs, and the sum of rich cultural globalization we are ready to face the new approach. What are global culture shapes people pull out every single one of their own culture; bring to the surface in the middle, and end up in a phenomenon known as global culture, its shape. Today, the amount of influence and power Brdygran (as a culture) there must be used wisely and technical means available to them earlier, naturally, a larger share of global culture designed for us in the future, they will. Thus, the active role and participation of the poor and strengthen the culture and cultural elements correction and dynamic reproduction of cultural elements and time will cause proportional changes. While taking advantage of the opportunities of globalization and find a place in world culture, we also maintain their culture. And interact with other cultures to flourish and Cultural Impact of birth is required to achieve this status, intellect, wisdom and trying to stay ahead of fast convoy Alsyrthvlat and human civilization. Just and reasonable to use the phenomenon of globalization, we must ponder and enter the world in a positive direction of the noble Islamic values and human propelled, and this is what kind of experience and knowledge with careful planning by local, national and international needs, to In order to create large markets and strengthen national cultures in a culture that has always been an important element of human social life has changed reached (hazegh, nikro, 1390, p. 11). Due to the positive and negative consequences of globalization, which cannot be indifferent to the passage of the active strategies and strategies but to enter the field?

\section{The proposed strategies:}

1. The promotion and strengthening of national, religious, and increased self-confidence in the ability of people to create a resistance against the invading alien culture.

2. The development of self-preservation, skills, and increased skills in youth and youth leaders to increase the diagnostic accuracy.

3. The depth of the Cultural Revolution in local, regional and international level to strengthen the foundations of the domestic and international arenas to strengthen the foundations of the Islamic world and the influence of cultural theory, as well as the idea of a good fit.

4. Wise management, artistic and meaningful flow of information and the use of superior technology and new media in the areas of domestic and international arena of ideas, beliefs and culture and the introduction of products and cultural products.

5. The strengthening of institutions and organizations committed to the traditions and culture of Iranian origin and faith for the deepening and development of culture and national and religious values.

6. Promote and increase the capacity of information technology, communications media, particularly affecting cross-border supply of culture, ideas and products.

7. Create the appropriate spaces of coexistence, tolerance of different cultures and ethnic groups in order to create unity and harmony.

8. Strengthening freedom, detailed, relevant and appropriate behavior model with rich Islamic culture in the social, economic and political.

9. Supply and introducing Islamic culture, history and national figures to young generations. 
10. Efforts to eliminate poverty reduction and social class intervals.

11. Movement based on justice and the strengthening of justice and justice and rich behavioral model in dealing with clients and equitable distribution of national resources.

12. The maintenance and proper use of national resources to identify and exploit the advantage of efficient and competent in public affairs, national and universal.

13. Strengthening the foundations of the country in order to prevent threats and perceived gaps in the global scene.

14. The planning application for the neutralization of threats, attacks and counter-cultural, disability, cultural globalization as one of the enemy.

15. Great Islamic culture and civilization in the world for global governance model to guide leaders.

16. Strengthening and developing a culture of anticipation and preparation of the internal spaces and environments, regional and global acceptance and readiness to accept and global governance.

17. Planning to take advantage of the opportunities emerging from the issue of globalization.

18. Tylygh and promotion of religious democracy and a model of democracy, scientific ideas and theories of logic and strong global levels.

19. Investment in cultural industries and information technology to the market new messages.

20. Assistance in planning for local, national and international macro level.

\section{Conclusions}

According to the above passage, little can be said in conclusion:

- According to the requirements and demands of globalization, political, social, economic and cultural self with, while challenging national and religious concepts and values, through the popularization and promotion of patterns of production, consumption and new life, beliefs and value systems of our society, the most important basis of social consensus and national unity, is targeted. National and religious values, whether religious duty or national mission, strategy requires rational and efficient in dealing with this phenomenon.

- National and religious values of Islamic culture and society, the ability to properly deal with this phenomenon and provide the foundations and structure of globalization is appropriate.

- A deep understanding of the challenges, threats and strategies, economic opportunities, social and cultural globalization and decent master thought necessary first step in dealing with this phenomenon. Fortunately a scattered effort in this area is formed. But that dispersed efforts, interacting with each other in a single thought and behavior turned.

- Globalization, with all the challenges facing our nation's culture and society, it also has created opportunities and capacity, ability to promote and convey the message of Islam's liberation, with all its capabilities in the world provides.

- And, finally, in the face of globalization strategies, as it happened, we can say that the implementation of strategies and opportunities that it creates. for the protection of cultural and social identity important part of our identity is to strengthen and enhance the social and cultural levels Gmarym efforts and protecting and preserving the rich culture and customs of the whole Islamic global is ready to face the new approaches to the interests of our country.

\section{References}

1. Honor, A., Check the face of globalization, Tehran, Institute for Strategic Studies, 1380.

2. Stiglitz, Joseph, at the New World, M. Karbassian, Fountain Press, 1386. 
3. John, Tamylsvn, globalization and Traditions M. sentence translation, printing Neil, Tehran, 1381.

4. The competent Nikravan, H., globalization and the proposed strategy with emphasis on national and religious values, 1390 .

5. Renan, M., without globalization we will never stay in Iran, Journal of Economics message, No. 14, April, 1383.

6. Saidi, R., Kia, AA, globalization and the role of the media in cultural identity, blessed Publications, Tehran, 1385.

7. Vedad HTML, Imran, interactive media and communication technologies for the XXI century, translator Ali Asghar Kia, publications of the development of radio, Tehran, 1379.

8. Friedman, Thomas, Thomas Friedman and Aegna Saver Amvnt debate about globalization, the translator Ali Divandari, jam, No. 295, the twenty-third of April, 1380.

9. Kazemi, Ali Asghar, globalization, culture and politics (the critical analysis of theoretical, epistemological), Tehran, Ghomes Publishing, 1380.

10. Rose, A., globalization, culture, identity, spreading straw, Third Edition, Tehran, 1386.

11. Gybrna, Montserrat, schools nationalism, nationalism and nation - state in the twentieth century - Translations Amir Masoud discretion broadcasting footage of State 1378.

12. Pieterse, Jan Nederveen, "Globalization as Hybridization", International Sociology, vol. 9, 265-291. (1993).

13. Castells, Manuel, "The Rise of Network Society", Oxford, UK: Blackwell. (1996)

14. Giddens, Anthony (1990), "The Consequences of Modernity", Stanford: Stanford University Press.

15. Held, David, "Democracy and the Global Order: From the Modern State to Cosmopolitan Governance", Stanford: Stanford University Press, UK: Cambridge University Press. (1995).

16. World Bank, "world development report", New York, p: 16. (1998).

17. Schien, Edgar H. "the missing concept in organization", Cornell university, p: 229 (1996). 